\title{
NARRATIVA DE UMA CLIENTE COM INSUFICIÊNCIA RENAL CRÔNICA: A HISTÓRIA ORAL COMO ESTRATÉGIA DE PESQUISA
}

\author{
THE NARRATIVE OF A CHRONIC RENAL FAILURE CLIENT: ORAL HISTORY AS RESEARCH STRATEGY \\ LA NARRACIÓN DE UNA DOENTE RENAL CRÓNICA: LA HISTORIA ORAL COMO ESTRATEGIA DE \\ PESQUISA
}

\section{Ana Maria Dyniewicz ${ }^{1}$ Eloísa Zanella ${ }^{2}$ Luciana Schleder Gonçalves Kobus ${ }^{3}$}

\begin{abstract}
RESUMO: O objetivo foi compreender os significados da doença renal para uma cliente há doze anos em hemodiálise ambulatorial. O estudo foi realizado entre novembro de 2002 a março de 2003 . Utilizou-se a História Oral e as categorias encontradas foram: A descoberta da doença renal e o cotidiano; O tratamento hemodialítico e seus limites; As preocupações com a auto-imagem; A esperança do transplante renal; Vínculo com a equipe de saúde; Apoio da família; Novos rumos para a vida; Tentativas para sentir-se útil. A narrativa da paciente mostrou como o tratamento é difícil, em uma vivência marcada por desafios, revelações e esperanças, empreendendo uma luta constante para vencer dificuldades, mas com capacidade de transcender o sofrimento. Destaca-se o vínculo e a segurança estabelecidos com a equipe de saúde, reforçando seu compromisso social e ético em relação de coresponsabilidade, envolvimento, cooperação, consenso, diálogo e espírito participativo. Reforça-se a importância de perceber cada pessoa como um ser único, singular, apresentando a sua maneira peculiar de conviver com a situação de doença.
\end{abstract}

PALAVRAS-CHAVES: Cliente Renal Crônico; Hemodiálise; História Oral.

ABSTRACT: The objective of this research was to understand the meanings of the failure kidney for a client who for twelve years is in hemodialisys treatment. The study was developed from November, 2002 through March, 2003. The Oral History as a research strategy showed the following categories: The failure kidney sick diagnostic discovery and the routine with it; The hemodialisy treatment and its limitation; The concerns about self image; The hopeness for a kidney transplant; The relationship with health professionals team; The family support; New projects of life; Attempts to feel itself useful. The patient's narrative showed how difficult is the treatment, dealing challenges daily, discoveries and hopes, a constant effort to fight against the limits, but demonstrating capacity to exceed the suffering. It was evident the positive and trustful relationship established with the health professional team, strengthening its social and ethical commitment in co-responsibility relationship, involvement, cooperation, consensus, dialogue and participative feelings. This study presents how important is to perceive each person as a singular one and the way that this person lives and deals with illness situation.

KEY WORDS: Chronic Renal Client; Hemodialisys; Oral History.

RESUMEN: El objetivo fue analizar la afectación de la enfermedad renal en un paciente con tratamiento de hemodiálisis ambulatoria desde hace doce años. El estudio se realizó entre Noviembre de 2002 y Marzo de 2003. Fue utilizada la historia oral y los parámetros encontrados fueron: la influencia del diagnóstico de enfermedad renal en la vida cotidiana; el tratamiento hemodiálico y sus limitaciones, las preocupaciones con la auto imagen; la esperanza de un transplante renal; el vínculo con el equipo de salud; el apoyo de la família; nuevos rumbos que toma la vida; intentos para sentirse útil. La descripción del paciente mostró la dificultad del tratamiento, que es una vivencia marcada por desafios, revelaciones y esperanzas, emprendiendo una lucha constante para vencer las dificultades, pero con capacidad de superar el sufrimiento. Destacándose el vínculo y la protección estabelecidos por el equipo de salud, reforzando su compromiso social y ético, en relación de co-responsabilidad, integración, cooperación, consenso, diálogo y espíritu participativo. Reforzando la importancia de percibir cada persona como un ser único, singular, presentando su manera peculiar de convivir con la enfermedad.

\footnotetext{
${ }^{1}$ Enfermeira, Doutora em Enfermagem, Professor de Metodologia da Pesquisa em Cursos de Especialização em Enfermagem na Faculdade Evangélica do Paraná. End: Rua padre Anchieta, 1965/1201. Curitiba - PR Fone: (41)-339-1184 E.mail: anadyni@netbank.com.br

${ }^{2}$ Enfermeira do Hospital Cristo Redentor - São Miguel do Oeste. Santa Catarina Especialista em Enfermagem em Nefrologia pela Faculdade Evangélica do Paraná. End: Rua 22 de abril, 1577. São Miguel do Oeste. Fone: (49) 622-3849. E-mail: eloisazanella@bol.com.br

${ }^{3}$ Enfermeira Especialista em Auditoria e Gestão em Saúde. Mestranda do Programa de Pós Graduação em Tecnologia em Saúde da Pontifícia Universidade Católica do Paraná. End. Av Silva Jardim 1411/02. Curitiba - PR Fone: (41) 3014-0594 E-mail kobus@netpar.com.br
} 
PALABRAS CLAVES: Paciente Renal Crónico; Hemodiálisis; História Oral.

\section{INTRODUÇÃO}

Enquanto a ciência médica evolui, aperfeiçoando o conhecimento, novos aparatos técnicos e especialização profissional tornam-se essenciais, a fim de garantir maior controle, diagnóstico e tratamento adequado às doenças. No entanto, apenas a tecnologia não é suficiente, há um nível mais profundo de necessidades humanas a serem alcançadas. Nele os profissionais de saúde, cada vez mais, são confrontados com a necessidade de humanizar as relações com os seus clientes.

Ser portador de uma enfermidade já é um desafio, no entanto, quando a doença é crônica, há o imperativo de se mudar hábitos, relacionados a dietas e/ ou atividades físicas, do uso contínuo de medicações, do enfrentamento da dependência de outras pessoas e aparelhos para adaptações a uma nova realidade de vida.

Para TRENTINI (1992) uma condição crônica de saúde caracteriza-se pelo momento em que a pessoa passa a incorporar a doença no seu processo de viver, constituindo-se em situação permeada de estresse. Seu impacto surge a qualquer tempo e com capacidade de causar alterações nas condições de ser saudável de pessoas e de grupos.

É relevante a questão apontada por Gualda, quando citada por GULLO et al. (2000), de que os portadores de doenças crônicas vivenciam muitos momentos junto a uma equipe multiprofissional, e desta maneira, estes profissionais devem aproveitar todos os momentos de interação para que sejam exploradas escolhas e mudanças possíveis de serem realizadas pelos pacientes, na busca de melhor qualidade de vida, apesar da doença.

Especificamente, a Insuficiência Renal Crônica impõe às pessoas uma série de modificações de atividades e novas perspectivas de vida, impulsionando-as à adoção de um modo de viver diferente, incluindo a dependência ao tratamento ambulatorial e auxílio constante de outras pessoas. Desta maneira, para a equipe de saúde, torna-se necessário estabelecer relações fundamentadas na confiança e compreensão, além de sólidos conhecimentos técnico-científicos. Caso contrário, a falta de aderência ao tratamento será mais um complicador na qualidade de vida do portador de doença renal crônica.

Stork apud SILVA et al. (2002) reflete sobre a questão da adesão do paciente renal crônico ao tratamento hemodialítico como sendo o resultado do difícil fato de se assumir sua condição crônica, no sentido de aceitá-la como parte da própria pessoa. Muitas vezes tal aceitação não é plena, mas parece estar relacionada a um acostumar-se com o que é ruim. Os autores descrevem ainda que muitos pacientes aceitam sua condição de saúde, porém experienciam momentos difíceis, de grande rejeição, culpa e lutas. Tal aceitação evidencia-se pela incorporação da própria doença e tratamento no seu cotidiano e na tentativa diária de conviver harmonicamente com sua condição de saúde.

Este artigo trata desta temática, trazendo o relatório de uma pesquisa em que se procurou conhecer as relações e as situações vividas por uma paciente ao longo de doze anos, ininterruptos, em tratamento hemodialítico, com a finalidade de evidenciar a importância de se desempenhar os cuidados de enfermagem de maneira coerente com as expectativas e necessidades dos clientes em tratamento ambulatorial. Para tanto, partiu-se do pressuposto de que compreender como vive uma pessoa portadora de doença crônica em tratamento ambulatorial há longa data, possibilita melhorar a assistência de enfermagem prestada ao conjunto de clientes da unidade, personalizando cuidados, transmitindo segurança, conforto, confiabilidade, pois são conhecidas suas situações do cotidiano, e em especial, as dificuldades e restrições a que são submetidos. 
Da mesma forma, o respeito pelas crenças, valores e costumes da pessoa cuidada possibilita a valorização do conjunto de suas relações sociais e com a equipe de saúde. Afinal, a aproximação do cuidador com a realidade vivida pelo portador da doença crônica possibilita compreender e atuar melhor diante de comportamentos e hábitos pregressos, bem como a sua capacidade de enfrentamento da doença, a fim de poder auxiliá-lo perante aos desafios de adaptação de novas atitudes e alternativas de hábitos de vida.

\section{REFERENCIAL TEÓRICO}

Segundo AJZEN \& SCHOR (2002) a Insuficiência Renal Crônica (IRC) é doença de alta mortalidade, com incidência e a prevalência de pacientes aumentando progressivamente no Brasil, bem como em todo o mundo. De acordo com inquérito realizado pela Sociedade Brasileira de Nefrologia, entre 1996 e 1997, as principais doenças reportadas como causa da IRC são Hipertensão Arterial, Glomerulonefrite e Diabetes Mellitus. Em sintonia com estes autores, RIELLA (1996) inclui ainda as Infecções Urinárias de repetição, lesões hereditárias (Doença Renal Policística), distúrbios vasculares, obstrução urinária, e o uso crônico de medicamentos ou agentes tóxicos.

No início do comprometimento da função renal, o indivíduo apresenta-se assintomático. A insuficiência renal torna-se crônica, segundo RIELLA (1996), quando há deterioração irreversível da função renal e elevação persistente da creatinina no organismo. Isto ocorre por falha na capacidade do organismo em manter o equilíbrio metabólico e eletrolítico, ocasionando a uremia. São definas quatro fases da instalação da doença:

$1^{a}$ fase: Diminuição da função renal, redução de mais ou menos $25 \%$ da filtração glomerular. Habitualmente não há aumento da uréia plasmática (azotemia).

$2^{a}$ fase: Insuficiência renal. Há redução de aproximadamente $75 \%$ da função renal. O rim já não tem capacidade de manter a homeostasia interna. Ocorre nictúria levando a distúrbio na concentração da urina, anemia e moderada azotemia.

$3^{a}$ fase: Ocorrem anormalidades mais persistentes no meio interno: azotemia intensa, anemia, acidose metabólica, hiperfosfatemia, hipercalcemia e hiponatremia. Geralmente a função renal está inferior a $20 \%$ da sua capacidade.

$4^{\mathrm{a}}$ fase ou fase terminal: predominam os sinais e sintomas da uremia (síndrome urêmica), o que indicam uma terapia substitutiva na forma de diálise ou transplante.

Dentre as manifestações clínicas da IRC, RIELLA (1996) discorre que os distúrbios metabólicos ocorrem pelo excesso do volume circulante devido a um aumento de sódio e água total, podendo ocasionar em Hipertensão Arterial, edema e Insuficiência Cardíaca Congestiva. Em alguns casos ocorre intolerância ao carboidrato, hiperlipidemia e Gota. Dentre as gastrintestinais encontram-se a anorexia, náusea, vômito, soluços e constipação ou diarréia. Podem ocorrer sangramentos em qualquer nível do trato gastrintestinal. O fluxo salivar fica diminuído, há aumento da sede, gosto metálico na boca, odor amônico na respiração, perda do olfato e paladar. Ocorre também Parotidite e Estomatite.

Com relação às diversas complicações enfrentadas pelos portadores de IRC, este mesmo autor cita como problemas neurológicos as alterações do estado do alerta e do sono, cefaléia, convulsões, irritabilidade, dificuldade de concentração. Dentre os problemas músculo-esqueléticos, encontram-se as cãibras, dor óssea, ptose dos pés e osteodistrofia renal. A palidez, a hiperpigmentação solar, pele seca e escamosa, prurido e alterações capilares são algumas dos acometimentos dermatológicos os quais o indivíduo portador de Insuficiência Renal Crônica se depara. Descreve os problemas endócrinos decorrentes da IRC destacando a possibilidade de hiperparatireoidismo, amenorréia ou hipomenorréia, decréscimo da fertilidade e deficiência estrogênica na mulher; já nos homens verifica-se atrofia testicular redução 
da espermatogênese, diminuição na síntese de testosterona, podendo ocorrer também diminuição da luz vascular, fibrose $e$ esclerose do epidídimo, levando a um dano reprodutivo irreversível. Em ambos a disfunção sexual com diminuição da libido está presente.

De uma maneira geral, várias propostas têm surgido com o objetivo de tornar a hemodiálise mais fisiológica com menos flutuações do volume extracelular, melhor estabilidade hemodinâmica e melhor equilíbrio eletrolítico, minimizando os sintomas a ela relacionados, ao mesmo tempo que promovem a remoção das toxinas urêmicas.

\section{METODOLOGIA}

\section{Descrição do local de estudo}

A Clínica Renal do Extremo Oeste funciona em uma unidade satélite, localizada no centro de São Miguel do Oeste /SC. É dotada de equipamentos e profissionais para atender três turnos, com 67 (sessenta e sete) pacientes em hemodiálise e 15 (quinze) em CAPD e 1(um) em APD, realizando três sessões semanais com duração de quatro horas para cada paciente. As sessões divididas em turnos de $2^{\circ}, 4^{\circ}$ e $6^{\circ}$ ou $3^{\circ}, 5^{\circ}$ e sábado. Atualmente atende-se 25 (vinte e cinco) pacientes/ dia em tratamento ambulatorial, procedente de São Miguel do Oeste e cidades vizinhas.

\section{Técnica para coleta e análise de dados}

A escolha da estratégia metodológica da pesquisa pela História Oral baseia-se na definição de Brêtas apud PELZER \& SANDRI ( 2002, p. 110) de que "a fonte oral é a base primária para a obtenção de qualquer forma de conhecimento (...) onde o registro escrito nada mais é do que a materialização daquilo que foi falado".

Segundo BRÊTAS (2000), em abordagem qualitativa, a História Oral tem por objetivo a formulação de documentação histórica e reflexão social, pois possibilita o resgate da memória individual e coletiva como a base primária de obtenção de qualquer forma de conhecimento, científico ou não. Desta maneira é definida por tudo aquilo que é obtido por meio da fala de alguém, desde que se preceda uma pesquisa básica sobre o tema em estudo, direcionando a formulação do roteiro de entrevista e oferecendo subsídios para a seleção de quem será entrevistado.

Partindo de várias bases teóricas sobre o assunto, a autora discorre que o conteúdo do depoimento de uma vida é marcado pelo coletivo, ao lado das particularidades e peculiaridades de um indivíduo, desta maneira o depoimento é útil pois mostra na singularidade e especificidade de uma constatação a construção do imaginário coletivo.

Especificamente, neste estudo foi utilizada a História Oral de Temática, a qual apresenta como característica a narração mais restrita de um depoente sobre um evento específico (BRÊTAS, 2000), e que nesta pesquisa trata do relato de uma pessoa portadora de insuficiência renal crônica há doze anos em hemodiálise.

Para HUMEREZ (1998, p.33) a narrativa de uma história permite desvelar faces que passam despercebidas da experiência humana, resgatando o sentido vivido pela pessoa que narra seu processo existencial. Assim "cada pessoa, no emaranhado das suas relações sociais, vai encenando sua história de vida cotidiana, a qual pode ser definida como o conjunto de atividades que relacionam diretamente o estar-no-mundo de cada um com os objetos que constituem a sua cultura".

Para a seleção da pessoa e ser entrevista levou-se em consideração a interação existente previamente entre ela e a entrevistadora, neste caso a enfermeira da clínica onde a paciente realiza as sessões de hemodiálise.

Foram realizadas quatro entrevistas, gravadas com a devida permissão da paciente, durante as sessões de hemodiálise. Posteriormente, as entrevistas foram transcritas, transformando as falas em documento escrito, submetido a limpeza de erros lingüísticos, repetições, tendo cuidando 
na preservação do conteúdo original e estilo de fala do entrevistada, conforme sugerem FRACOLLI et al. (2000).

Após esta fase, foram identificados os temas e as categorias, permitindo representar um significado próprio da história de vida da paciente, a partir do olhar do presente, cujas memórias foram paulatinamente validadas, para buscar melhor compreensão, reflexão e captação da história em processo, finalizando na análise do texto narrado qualitativamente em decorrência da natureza da pesquisa.

\section{APRESENTANDO E ANALISANDO AS CATEGORIAS}

\section{Dados de identificação}

M.A.R, sexo feminino, 51 anos de idade. Em 19 de dezembro de 1991 foi admitida na Clínica de Nefrologia e submetida ao tratamento hemodialítico. Foi instalado um cateter na veia jugular direita de permanência temporária. Posteriormente, iniciaram-se as sessões de diálise, com permanência de 4 horas, por três vezes por semana, distribuídos nos dias de $2^{\circ} 4^{\circ}$ e $6^{\circ}$ feiras.

Apresentou os seguintes sintomas urêmicos, por um longo período: pressão alta persistente, letargia, prurido, cansaço, inchaço nas mãos e tornozelos e freqüentes distúrbios de sono, perda do apetite, dispnéia a qualquer esforço físico e repetidas infecção urinárias.

Diagnosticada como portadora de Nefroesclerose Hipertensiva em 1992 realizou-se a confecção de uma Fístula Artério Venosa (FAV). Realizou-se uma biópsia hepática em janeiro 1998, que teve como resultado hepatite C crônica, em discreta atividade. Outras complicações ocorreram, tais como: Anemia, diminuição da capacidade de realizar exercícios, Infecções Respiratórias, Infecções Urinárias, Osteoporose, Hiperparatireoidismo e Osteodistrofia.

\section{A descoberta da doença renal e o cotidiano}

A descoberta do diagnóstico da doença renal está relacionada à presença de sintomas que levaram a procura de atendimento de saúde. No entanto, devido à pouca conscientização de uma parcela significativa da população quanto às ações de prevenção que promoveriam a detecção precoce das doenças, os doentes descobrem seu problema na fase em que as complicações já estão presentes. Esta situação faz com que sejam necessários procedimentos invasivos com maior rapidez, os pacientes se vêm diante de materiais e equipamentos que as assombram, desencadeando medos e receios compreensíveis.

As falas da cliente têm muito desta realidade:

"Bom, chegou o momento, a enfermeira chegou, arrumou as coisas e o médico foi explicando os detalhes, fez anestesia local, me deu um banho de um líquido o tal "PVPI", fiquei feia..., pescoço dolorido, não conseguia mexer,... Logo fui para máquina, estava com dor no pescoço, nas costas, vomitei, passei muito mal na máquina, pois toda hora apitava uma coisa, o meu sangue passava de uma linha para outra, estava presa àquela máquina."

Segundo RIELLA (1996) no início da doença, que é geralmente lento, os sintomas são fadiga, letargia, cefaléia e fraqueza geral. A síndrome urêmica ou uremia é o termo utilizado para designar as manifestações da disfunção renal crônica, acarretada pelo acúmulo de substâncias tóxicas na corrente sangüínea, normalmente excretadas na urina. Esta sintomatologia foi vivida pela entrevistada:

"Eu iniciei hemodiálise após várias infecções urinárias e pressão alta. Sentia cansaço, perda de apetite, vômito, náusea, pressão alta. Fui internada várias vezes em minha cidade, lá me davam remédio para pressão alta, diurético para mim urinar e para baixar a pressão. Tomava, mas o 
mal estar, a falta de apetite e o cansaço continuavam... sei que não estava bem fisicamente, urinava pouco, mesmo com diurético."

Sintomas como náuseas, vômito, cansaço, falta de apetite são considerados como situações dolorosas e desconfortáveis, pela grande maioria dos pacientes que se submetem ao tratamento hemodialítico; tais situações apresentam conseqüências metabólicas; psicossociais, tal como a dificuldade de executar tarefas habituais; comportamentais e fisiológicas, que podem levar à necessidade de outras intervenções farmacológicas para controle dos sintomas. Estudos comprovam que além dos fatores catabólitos inerentes à insuficiência renal crônica e aos métodos dialíticos, a presença de desnutrição energético-protéica está comumente associada ao baixo consumo alimentar. Outros fatores relacionados à presença de desnutrição são o tempo de diálise, a associação com diabetes, a eficiência da diálise, entre outros (VALENZUELA et al., 2003).

O medo torna-se recorrente e mostra-se relacionado à preocupação com o futuro, à separação, pela possibilidade de morte e incertezas quanto aos problemas que poderão agravar-se com o tempo. O medo de morrer é enfocado como conseqüência da doença, tal como refere a entrevistada:

"O médico chamou a família conversou e colocou a situação: você tem doença renal, o rim parou de funcionar, e você precisa dializar, fazer hemodiálise toda vida, senão pode piorar... Enquanto isso, chorei. Pensei porque eu? O que aconteceu com meu rim? Quem vai cuidar de mim? Vou morrer? Fiquei tensa, inquieta, com dores nas costas. Deram-me tranqüilizante... ansiedade, medo, já sentia gosto de urina na boca e não tinha apetite."

SIQUEIRA (2003), dentre outros autores, declara que a questão da morte é inadequadamente tratada ainda na formação dos profissionais de saúde. Complementa argumentando que os próprios profissionais encontram-se despreparados para conduzir com proficiência este sofrido momento da vida dos pacientes. Que a medicina praticada atualmente, embora permeada de sofisticada tecnologia, subestima o conforto do enfermo terminal, causando agonia para o paciente, sua família, sem mencionar o ônus financeiro imposto ao sistema de saúde. Neste sentido, faz-se mister "resgatar sentimentos como compreensão, solidariedade e compaixão, sem o quais estaremos fazendo uma ciência fria que não contempla a dignidade do ser humano", conclui SIQUEIRA (2003, p.07). Estas declarações levam-nos à reflexão de que se não desenvolvermos tais sentimentos para com aqueles de quem cuidados, não saberemos como conduzi-los a uma passagem por uma doença terminal de maneira digna.

"Entrei em programa de hemodiálise três vezes por semana ... tudo é novo, conviver com a dor, com o cateter, com o medo, a angústia, o fim da linha."

LIMA \& LIMA (1983) enfatiza que existe uma situação de estresse onde a ansiedade se faz pressente e constante durante todo o tratamento. A convivência com a dor e o medo reflete a angústia, a falta de perspectiva, mas também não devem ser tomadas como "fim da linha". Não se pode desprezar o instinto de preservação dos indivíduos, mesmo porque desprezar atitudes é um ato impregnado de racionalidade, e revela uma dificuldade em lidar com as próprias limitações e fraquezas. Neste sentido a preservação da vida esta intimamente ligada na busca de um alívio do próprio sofrimento.

\section{O tratamento hemodialítico e seus limites}

Em relação ao em tratamento hemodialítico após a descoberta da doença renal, houveram diferentes reações expressas pela paciente: o medo do hemodialisador, o estresse pelas freqüentes solicitações para realizar procedimentos de rotina, os receios pelos efeitos colaterais do tratamento e as cobranças pela equipe de 
cliente com insuficiência renal crônica: a história oral como estratégia de pesquisa. Revista Eletrônica de Enfermagem, v. 06, n. 02, p. 199-212, 2004. Disponível em www.fen.ufg.br

saúde para manutenção de níveis pressóricos normais, dieta, ingesta de medicamentos, tais como mostram os recortes das falas a seguir:

"Tinha medo que a máquina parasse ou ocorrer um defeito durante a sessão, causando mais medo, fiquei tensa, nem me mexi, de medo... Falei para enfermeira: amanhã não volto mais...mas ao mesmo tempo sabia que seria necessário...para viver."

WALACE (2003) salienta que, na opinião dos clientes, o hemodialisador representa a limitação da própria vida, acrescido dos receios e ansiedades de problemas que possam haver com a máquina, trazendo conseqüências ao tratamento e preocupações com a continuidade da terapia.

TURRA et al. (2001) tratando das repercussões da doença crônica na qualidade de vida de adultos, mostram o quanto esta condição se torna uma fonte de tensão à medida que esta impõe outros desafios e novas incumbências ao indivíduo, como fazer dieta, tomar medicações, e o fato da possibilidade de enfrentar desarmonias fisiológicas e restrições indesejáveis.

Nesta mesma linha de raciocínio, SILVA et al. (2002), citando diversos autores, relatam que ainda não existem estudos que confirmem que os avanços tecnológicos os quais permitiram a evolução assistencial aos indivíduos portadores de IRC tal qual como vivenciamos atualmente, efetivamente favoreçam os pacientes no sentido de uma melhor qualidade de vida. A realidade é que alguns estudos descrevem uma perspectiva negativa do viver com a IRC, a qual é considerada, de uma maneira geral, "uma doença estressante, que afeta a qualidade de vida e traz importantes limitações físicas, psicológicas e sociais" (SILVA et al., 2002, p. 563).

As falas de M.A.R. tratam desta questão, como mostra a seguir:

"Sinto-me presa ao hemodialisador, tenho medo da máquina parar. Tive de me acostumar com o tamanho da máquina e que causa câimbra, hipotensão, ânsia, dor de cabeça e nas costas pelo tempo que se fica deitado na poltrona ...várias picadas de agulha na barriga, acordar cedo, esperar o motorista... O que não falta é recomendações: não tomar muito liquido, não comer sal, não comer comida que possui potássio, moderar o fósforo, medicações para pressão, pros ossos, pro estômago, pra dor, pras viagens o tal Dramin ... mas é a única forma de sobreviver... eu tenho que me adaptar com tudo isso e muito mais...às vezes não consigo ficar o tempo todo na missa, preciso sentar."

A paciente entrevistada se percebe tendo que mudar seus hábitos alimentares e atividades de toda a vida, incidindo assim a angústia e o sofrimento, os quais vão interferir na sua relação cotidiana tanto com a vida, como com a daquelas que a rodeiam.

\section{As preocupações com a auto-imagem}

A alteração da auto-imagem é mencionada por M.A.R. como causa de sofrimento e é fator marcante do início do tratamento, como fator discriminador, tal como expressa M.A.R:

"Passaram um cateter no pescoço e eu tinha que retirar o colar .. pensei.. não vou usar mais colar, vou ficar sem nada, vou ficar feia..o que os meus amigos vão falar com esse cateter no pescoço,..??!! Vão pensar que tenho AIDS.. eu não consigo entender mais nada vou ficar louca... queria morrer."

0 uso do cateter relaciona-se à alteração da auto-imagem e se associa à dependência da hemodiálise, o que a torna diferente das demais pessoas, gerando sentimento de angústia e tentativa de isolamento. Autores como LIMA \& GUALDA (2001) contemplam que, por vezes, o aparecimento dos primeiros sinais e sintomas da patologia, juntamente com o início das alterações corporais são o primeiro contato com a realidade da manifestação da doença, 
e estas geralmente vêm acompanhadas de sentimentos de medo, tristeza e desespero.

TURRA et al. (2001, p. 33) citando Romano, descrevem que "na ocorrência de uma doença orgânica a imagem que o indivíduo tem do seu corpo é mudada imediatamente, toda estrutura motriz dos instintos de vida do sujeito passa a ser focalizada no órgão do doente" e tais alterações orgânicas ativam as emoções do indivíduo, reestruturando sua imagem corporal.

\section{A esperança do transplante renal}

Em relação aos transplantes renais, MEDINA et al.(2002) relatam que no Brasil existem cerca de 46.000 pacientes em diálise. Em 2001 foram realizados 3.099 transplantes, sendo $1.256 \mathrm{com}$ doador cadáver. As leis no 9434/97 e 10211/01, do Congresso Nacional estabelecem os critérios para doação de órgãos de cadáver e de doador vivo. Os critérios para diagnóstico de morte encefálica foram estabelecidos pela Resolução do Conselho Federal de Medicina $n^{\circ}$ 1480/97 com base no diagnóstico clínico, comprovado por ao menos um exame subsidiário. Entretanto, o principal obstáculo à doação continua sendo a não-identificação do doador e a ausência de sua notificação às centrais de captação, através de uma abordagem adequada.

Esta realidade é de conhecimento da paciente:

"Conversaram sobre a diálise; sobre transplante, que em breve fariam...até parece, estou há doze anos em hemodiálise e não transplantei, estou com o protocolo de transplante em dia ..... mas falta captação...vou esperar...tenho força "

"Muitas vezes, me sinto só, desacredito na cura, mas conservo a esperança de transplante, pois para mim transplante é a cura. Eu só queria pedir que as pessoas fossem mais favoráveis á doação de órgãos. As filas de espera são enormes e o sofrimento também."
A paciente revela na sua narrativa que se encontra em meio a sentimento conflitante, levando-a experimentar a esperança e a falta dela. Isto envolve medo e sofrimento, condicionado à realidade e à evolução clínica de sua doença. Tendo consciência de seu medo, procura em si mesmo algo em que possa se apoiar, e a esperança é um destes apoios. Enfrentar esta situação desafia suas emoções, e ela busca superar esta crise transformando-a em oportunidade para o crescimento pessoal.

Neste sentido, Bury apud LIMA \& GUALDA (2001) afirma que para manejar o desenvolvimento do processo de doença crônica e tentar viver normalmente, o paciente emite repostas ativas frente aos desafios, que englobam mecanismos cognitivos e emocionais de acordo com a sua identidade e seu estilo de vida. O indivíduo que adota estas estratégias adaptativas, as quais podem ser traduzidas no termo "Coping", têm o poder de transformar a doença num processo construtivo. Assim, situado no contexto do curso da vida da pessoa, a situação poderá se articular com experiências do passado e do futuro, levando o paciente a experimentar novos caminhos e conseqüentemente fazer uma reconstrução da sua existência. A vivência do sofrimento parece ser oportunidade para descobrir e refletir sobre o lado difícil e doloroso da vida., a vivenciando de outra maneira, aprendendo lições enquanto enfrenta o sofrimento e o compartilha com outras pessoas.

"Com o que tenho vivido me deparei com várias pessoas com o mesmo problema... até uma menina e ela sorriu para mim e disse: eu passei por tudo isso e venci..., fiz transplante hoje estou muito bem.... Então, pensei, também vou vencer e realizar transplante logo, isso deixou-me esperançosa, a vida neste instante tornou-se mais interessante e agradável"

Embora o enfrentamento da doença renal seja solitário, a paciente sente-se ajudada por outros em situação semelhante, 
recebendo apoio e solidariedade. Ela se sente ajudada e com esperanças que pode ser submetida a transplante renal, que seu sofrimento atual irá terminar.

\section{Vínculo com a equipe de saúde}

A equipe de saúde pode desempenhar um papel fundamental no enfrentamento do paciente e sua família quando inseridos num processo de doença crônica. Neste sentido, HORA et al. (2001) afirmam que o trabalho da equipe de enfermagem junto ao paciente e sua família deve prever uma rede de apoio de diversas naturezas, numa abordagem multidisciplinar. A equipe deve desenvolver grande habilidade de observação, facilidade para o diálogo e capacidade de abstração, a fim de ser capaz de situar os problemas vivenciados pelo paciente e sua família dentro do contexto cultural e social no qual se encontram.

HOFLING et al. (1970) e ERICKSON (1971), consideram que o desenvolvimento do sentimento de confiança na equipe de saúde depende do modo pelo qual as necessidades básicas do paciente foram satisfeitas, nos seus primeiros dias de tratamento, pelas pessoas que lhe foram significativas. Se 0 atendimento desta necessidade não foi suficiente, o paciente poderá tornar-se um ser desconfiado e inseguro.

"O atendimento ... os auxiliares são amigos conversam, brincam, trocam idéias, colaboram conosco, participam de nossas angústias, atendem rápido, deixam a gente dormir quando estamos a fim, conhecem a história de vida de cada um, compram coisas...

"A equipe sabe mais de nós que nós mesmos, avaliam a dor e o desconforto, diminuem a ansiedade, o medo, pois tem uma auxiliar para três pacientes, na outra unidade eram nove pacientes para dois auxiliares, hoje me sinto mais protegida, pois elas aceitam o paciente como ele é, não reparam na roupa que estão vestidos, permanecem com $o$ paciente até que o motorista chega, muitas vezes passo mal após e lá estão elas prontas para socorrer."

Embora encontremos na literatura um consenso do papel fundamental da equipe de enfermagem dentro de organizações de saúde, na prática estes profissionais desconhecem a teia de poder que permeia todas as dimensões das suas práticas, o qual interfere no planejamento e na qualidade da assistência prestada. A falta de poder político leva a enfermeira ao desenvolvimento de ações de dependência, ou seja, para o outro e não com o outro. Esta realidade, por vezes, acarreta um distanciamento da enfermeira do paciente, não lhe permite perceber ou escutar as suas reais necessidades, desenvolvendo, assim, ações incompletas e fracionadas.

A concepção de corpo como está vigente no setor saúde reitera a dicotomia corpo-mente, corpo-alma e leva a enfermeira a desenvolver uma prática norteada apenas pela ciência e pela tecnologia. Assim, não valoriza o corpo do paciente nem dos profissionais de saúde, como corpos viventes com a sua história, com os seus direitos e deveres, não considerando o humano nas relações com o outro com o mundo e consigo próprio (POLAK, 1996).

A equipe de saúde deve estar orientada para o cuidar, mas existem fatores que podem influenciar no alcance deste objetivo, entre eles o fato de que existem indivíduos diferentes técnica, social e psicologicamente. A busca do resultado no processo de cuidar pode sofrer interferências se não houver espírito de união, de maneira a não comprometer os objetivos da equipe multidisciplinar.

A paciente relata em vários momentos sua capacidade para transcender seu sofrimento, não se prendendo aos aspectos negativos, mas buscando amenizar o sofrimento relacionado ao processo terapêutico. Ressalta o bom vínculo com equipe da saúde, indicando que a sua atuação deve procurar atingir o paciente em suas dimensões biológicas, psicológicas, sociais. Faz parte do papel do enfermeiro estar ciente das dificuldades e aptidões da equipe em que está inserido e contribuir para 
o seu desenvolvimento, incluindo questões relacionadas à humanização da assistência em todas as suas atividades de educação continuada, formais e informais.

A comunicação, com todos os seus poderes de negar, confirmar, desconfirmar e passar dupla mensagem, é comentada exaustivamente no trabalho de GULLO et al. (2000, p. 210), citando diversos autores, quando discorrem sobre a sua importância no estabelecimento de um vínculo terapêutico. $\mathrm{E}$ neste vínculo, o enfermeiro ocupa papel preponderante uma vez que passa muito tempo em contato com o paciente e " tem ampliada sua capacidade de observação, podendo detectar expressões verbais e não verbais indicativas de situações relevantes, sobre as quais poderá interagir"

Outro aspecto a destacar é a diferença significativa entre informar no sentido de dar notícias ou avisar, e comunicar no sentido de entender-se em confiança, respeito, sinceridade e autenticidade. A narrativa de M.A.R. parece carecer deste último tipo de comunicação, pois há práticas em saúde nas quais acontece o exercício do monólogo, suprimindo-se diálogo que subentende comunicação e desafio entre duas ou mais pessoas. Especificamente na Enfermagem, esta compreensão é significativa. STEFANELLI (1993) refere-se à comunicação como algo mais que um instrumento básico de enfermagem ou do desenvolvimento do relacionamento terapêutico, que deve ser considerada como capacidade ou competência interpessoal a ser adquirida pelo enfermeiro (na atenção) às necessidades do paciente, em todas as suas dimensões, levando em consideração a sua cultura e ambiente.

\section{Apoio da família}

SILVA et al. (2002, p. 566) descrevem, citando diversos autores, que a avaliação de uma pessoa em relação à sua qualidade de vida está muito relacionada ao apoio que recebe da família, e que este fato a faz sentir melhor. Consideram que "a doença, de uma certa forma, também é da família e, quando os familiares estão presentes, dando apoio constante, a dor do doente renal crônico é compartilhada, diluída".

"Encontrei meu marido, ansioso, preocupado comigo, o que me deixou mais feliz, pois eu sábia que alguém estava junto comigo e sentia muitas coisas semelhantes a minha, e que nós iríamos superar juntos as dificuldades. Me abraçou...conversamos... falei da diálise; da menina...enfim diminuiu o medo, a ansiedade."

"Retornei para casa... tudo estava em ordem, todos me esperando felizes por eu estar chegando, foi uma emoção que nem tenho palavras pra explicar... contei a eles tudo...todos se dispuseram a me ajudar, as filhas com os medicamentos e com a dieta. O meu filho foi algumas vezes comigo até a clínica de diálise."

Para a paciente, a família é considerada com um bem maior, revelando uma convivência harmoniosa, voltada para a freqüente demonstração de afeto mútuo, em articulação com as preocupações do dia-adia. Ao mesmo tempo, relata a dificuldade de poder exteriorizar seus verdadeiros sentimentos, tendo em vista as transformações que vêm ocorrendo nas relações familiares. As falas demonstram motivação e alegria, e ao mesmo tempo tristeza e sofrimento, pelo tratamento ser algo difícil de se enfrentar.

Segundo GONÇALVES et al. (1996), em relação à doença crônica, verificou-se a tendência para a concentração das responsabilidades de cuidado ou ajuda num cuidador único na família. Neste estudo, notase que o cônjuge desempenha este papel. As autoras reforçam que a qualidade de vida tão desejada a ser vivida no contexto familiar depende do empenho dos familiares junto ao doente, amparando-o, não o negligenciando ou fragilizando. Para tanto o cuidador único não deve se sobrecarregar ou se estressar até a exaustão. Neste estudo, parece haver o compartilhar de cuidados entre os membros da família quanto aos cuidados com a dieta, a administração de medicamentos, o quê 
mostra uma resposta positiva unânime frente às necessidades diárias da paciente.

Em meio a tanto sofrimento, a paciente mostra não se render perante a doença crônica. Luta com determinação, apoiada na fé, a profunda ligação que paulatinamente foi estabelecendo com Deus. Encara as dificuldades tentando romper barreiras, buscando ajuda, tomada de esperança que não lhe permite desanimar.

"No início do tratamento, não conseguia ir na igreja; pois pensava: por que Deus fez isso comigo?... mas com o decorrer do dia-a-dia vi que é muito importante compartilhar nossas dificuldades com Deus. Rezo e peço proteção para minha família, para meus netos, para equipe de diálise, enfim agradeço todos os dias pela vida."

PELZER E SANDRI (2002) refletem sobre a espiritualidade relatando que nos últimos anos os enfoques na dimensão espiritual da saúde têm revelado que a sua prática, ligada à religiosidade, causa benefícios físicos, podendo prolongar a sobrevivência em condições crônicas.

\section{Novos rumos para a vida}

SILVA et al. (2002) comentam que não existem referências na literatura acerca do modo como as pessoas com problemas renais crônicos encaram seu futuro. O que se relata são fases de adaptação ao tratamento hemodialítico, de um período inicial de "lua de mel", seguido pelo desencanto. Por fim, a adaptação a longo prazo, quando as pessoas finalmente alcançam um nível de aceitação da sua doença e suas limitações, procurando aliar atividades que lhe tragam prazer ao seu cotidiano permeado por situações desgastantes em todos os aspectos da sua integralidade como ser humano:

“(..) mas como iriam ficar meus filhos, netos e meu marido, que sempre esteve presente nos momentos tristes e alegres, me ajuda, me dá força... Trabalha para dar as coisas para mim, e para a família... tenho que ser forte. Não quero morrer."

A narrativa mostra o adoecer acompanhado de insegurança e ansiedade, provocando expectativas sobre projetos de vida, bem como as evidências da importância das relações familiares.

Esta percepção impossibilita ver a doença dissociada da existência humana, o que a transforma em um problema existencial. A saúde e a doença do homem fazem parte da sua trajetória, estão inscritas no seu corpo, como está a vida, a alegria, a dor, enfim tudo o que diz respeito ao homem. Assim, saúde e doença são formas de comportamento, refletem as relações do homem consigo, com o outro e com o mundo, comprometendo o ser total que é o homem, ou seja o seu corpo e o mundo (POLAK, 1994). Segundo uma das entrevistadas:

"Enquanto isso eu organizei minhas coisas, ... pensei nos meus filhos, nos meus netos.... na minha vida, no que eu ia fazer de agora em diante... Estava só, senti medo, ansiedade, nervosismo, estava angustiada, presa àquele quarto."

\section{Tentativas para sentir-se útil}

Para LEVY (1990), os pacientes renais submetidos à diálise vivem uma vida social bastante alterada. Encontram-se dependentes de uma máquina, forçados a um ritual diário e repetitivo de troca de soluções medicamentosas, expostos a contínuo estresse emocional, submetido a um regime de múltiplas perdas: emprego, liberdade e expectativa de vida. Este aspecto podemos verificar na fala abaixo:

"Tenho que me organizar com as tarefas de casa, cuidar das roupas enfim dos afazeres e vender os meus perfumes para ajudar no orçamento da casa.... comprar presentes para os netos... Meu marido não deixa faltar nada, mas gosto de ajudar, enquanto isso, converso com as pessoas... e elas 


\section{me ajudam... não fico em casa pensando coisas ruins."}

O fato de poder continuar suas tarefas rotineiras como o trabalho em casa, cuidados com filhos e familiares e alguma forma de ajuda financeira são tentativas de adaptações cotidianas cujas restrições manifestadas pela paciente demonstram a dimensão de seu sofrimento pelas limitações impostas pela doença renal. Ela se vê obrigada a submeterse a um tratamento extremamente agressivo, tendo que se adaptar às restrições tanto de atividades quanto de relacionamento.

MC DOUGALL (1989) tece comentários a respeito das reações do ser humano, dizendo que: "todos visam aos mesmos objetivos: o desejo de se manter vivo, de se realizar, de conservar intacta a identidade constituída e de defender-se contra tudo o que ameaça esses propósitos. A força do sujeito reside nessa continuidade e nessa monotonia".

\section{CONCLUSÃO}

Neste estudo buscou-se entender a vivência da paciente dentro de uma concepção menos mecanizada, priorizando as suas interações sociais, familiares e com a equipe de saúde. Neste sentido, compartilhamos das idéias de Kleinman apud LIMA \& GUALDA (2001), quando discorre sobre a importância de se centrar as atividades dos profissionais envolvidos no cuidado a pacientes renais crônicos não só nos aspectos da doença propriamente dita, mas também na experiência de vida destes pacientes, e dos seus familiares, considerando a maneira com entendem, respondem, se adaptam e lidam com os sintomas da doença e problemas relacionados.

No decorrer da análise foi possível perceber o quanto a experiência com a doença renal crônica é complexa e como são muitas as limitações da paciente na sua vida social e familiar. Ficou explícito a exigência do enfrentamento permanente com a doença colocando-a à margem de uma vida social normal.
O enfrentamento da cronicidade da doença renal envolve a compreensão pelo paciente sobre o seu significado, e dos reflexos no seu cotidiano: nas relações, na concepção de vida, devido às alterações físicas e emocionais que representam obstáculos ao seguimento do tratamento. Tratamento este que engloba a hemodiálise, a dieta, incluindo o acesso ao serviço e outras questões que o deixam exposto a uma vastidão de eventos que promovem medo, angústia e insegurança.

A narrativa da paciente mostra uma vivência marcada por desafios, revelações e esperança, empreendendo uma luta constante para vencer dificuldades sem se render a elas. Uma das características centrais é sua determinação para mobilizar suas forças para continuar o tratamento. Apoiada pela família, não se permite deixar levar pelo desânimo e por pensamentos negativos. Buscando ajuda, ancorada na sua fé em Deus, renova suas esperanças de que possa ser submetida ao transplante renal.

O estudo mostrou a necessidade de percebermos cada paciente como um ser único, singular, com uma maneira peculiar de viver a sua situação de doença. Desta maneira as intervenções de enfermagem também devem ser cada vez mais individualizadas, fugindo das normas rígidas que otimizam dinâmicas organizacionais e nada trazem de benefício ao doente. Sendo assim, deve-se dar importância à percepção de que cada paciente tem de sua vida, saúde, doença, considerando suas sugestões para soluções de seus problemas, desenvolvendo então, um trabalho voltado ao doente e não à doença.

A paciente mostra a sua capacidade de transcender o sofrimento pela tentativa de não se prender apenas ao aspecto negativo do processo da doença e através do estabelecimento de um vínculo que lhe transmita segurança entre ela e a equipe de saúde.

Desta maneira a organização do cuidado de enfermagem necessita de caminhos eficazes e técnicas seguras as quais atenuem o sofrimento do paciente renal crônico. $\mathrm{Na}$ verdade, o cuidado é um 

cliente com insuficiência renal crônica: a história oral como estratégia de pesquisa. Revista Eletrônica de Enfermagem, v. 06, n. 02, p. 199-212, 2004. Disponível em www.fen.ufg.br

compromisso social ético, solidário, despojado de qualquer interesse unilateral, tendo como objetivos a recuperação da saúde, reintegração da pessoa no seu meio social e o desenvolvimento do potencial criativo tanto do profissional como do(s) ser(es) cuidado(s). O cuidado deve é precedido de intencionalidade, exigindo-se nesta relação co-responsabilidade, envolvimento, cooperação e espírito participativo de ambas as partes. Deve-se respeitar as diferenças, não devendo existir uma imposição hierárquica por parte do profissional, mas sim a realização de um trabalho que considere o paciente e sua família, tendo como objetivo comum a melhora das condições de saúde e de vida das pessoas.

\section{REFERÊNCIAS BIBLIOGRÁFICAS}

AJZEN, H.; SCHOR, N. Nefrologia. São Paulo: Manole, 2002.

BRÊTAS, A. C. P. Pesquisa qualitativa e o método da história oral: aspectos conceituais. Acta Paul. Enf. v. 13, n. 3, p. 81-91, 2000.

ERICKSON, E. H. Oito idades do homem. In: Infância e sociedade. 2.ed. Rio de Janeiro: Zahar, 1971.

FRACOLLI, L.A. et. al. Enfermagem em doenças transmissíveis: como abordar 0 tema na graduação em enfermagem? Rev. Esc. Enf. USP. v.34, n.4, p.395-400, 2000.

GONÇALVES, L. H. T et. al. A percepção dos idosos quanto seu estado de saúde e apoio familiar. Cogitare Enferm., v.1, p.65, 1996.

GULLO,A.B. et..al. Reflexões sobre comunicação na assistência de enfermagem ao paciente renal crônico. Rev. Esc. Enf. USP. v.34, n.2, p. 209-12, 2000.

HOFLING,C. K. et. al. Comprensión de las relaciones entre enfermera y paciente. In: Enfermeira psiquiátrica. Mexico: Interamericana, 1970.

HORA, E.C. et. al. Aliando-se ao paciente e à família diante das incapacidades. Rev. Paul. Enf., v.20, n.2, p. 52-56, 2001.

HUMEREZ, D.C. História de vida: instrumento para captação de dados na pesquisa qualitativa. Acta Paul. Enf. , v.11, n.3, p.32-37, 1998.

LEVY, N.B. Psychopharmocology in patients with renal failure. Ins. G. Psychiatry., v.20, p.303, 1990.

LIMA, A.F.C; GUALDA, D.M.R. Reflexão sobre a qualidade de vida do cliente renal crônico submetido à hemodiálise. Nursing. $\mathrm{n}$ 4. 2000 .

O significado da hemodiálise para 0 paciente renal crônico: utilização de um modelo para a interpretação de dados de pesquisa qualitativa. Rev. Paul. Enf., v.20, n.2, 2001.

LIMA, M.G; LIMA, A .C .L. Pacientes renais crônicos e transplantados. São Paulo: GBM, 1983.

McDOUGALL, J. W. Defesa de uma certa anormalidade - teoria e clínica psiconalítica. Porto Alegre: Artes Médicas, 1989.

MEDINA, P. J. O., et al. Guia clínico para o transplante renal. J. Bras. Nefrol., v.15, p 311-312, 2002.

PELZER, M.T.; SANDRI, J.V.A. O viver e ser saudável no envelhecimento humano contextualizado através da história oral. Rev. Gaúcha Enf., v. 23, n.2, p. 108-122, 2002.

POLAK,Y. N. S. A compreensão de doença dos adultos da grande. Cogitare Enf., v.1, n.2, p.11-18, 1994.

A concepção de corpo no mundo da Saúde. Cogitare En., v.1, n.1, p. 4-9, 1996. RIELLA, M. C. Princípios de nefrologia e distúrbio hidroeletrolítico. $3^{a}$ ed. Rio de Janeiro: Guanabara Koogan, 1996.

SILVA, D.M.G.V. et. al. Qualidade de vida de pessoas com insuficiência renal crônica em tratamento hemodialítico. Rev. Bras. Enf., v. 55, n.5, p. 562-567, 2002.

SIQUEIRA, J.E. Sobre a morte e o morrer: tecnologia ou humanismo? Rev. Assoc. Méd Bras , v.49, n.1, p. 1-23. 2003.

STEFANELLI, M. C. Comunicação com paciente - teoria e ensino. São Paulo: Robe, 1993.

TRENTINI, M., SILVA, D.G.V. Condições crônica de saúde e o processo de ser saudável. Texto \& Contexto Enf., v.1, n.2, p.76-78, 1992

TURRA, K. et. al. As repercussões da doença cardiovascular na qualidade de vida de 

de Enfermagem, v. 06, n. 02, p. 199-212, 2004. Disponível em www.fen.ufg.br

adultos: relato de experiência. Cogitare Enferm.,v.6, n.1, p32-36, 2001.

VALENZUELA, R.G.V et. al. Estado nutricional de pacientes com insuficiência renal crônica em hemodiálise no Amazonas. Rev. Assoc. Méd. Brás., v.49, n. 1, p. 72-8. 2003.
WALACE, M.C.P. Psicologia - renais crônicos. [on line]. Disponível em $<$ www.intermega.com.br/intermega/index.php $>$ Acesso em 24/02/03

Texto recebido em 03/05/2004.

Publicação aprovada em 31/08/2004 